\title{
Dry and wet rainy seasons in the Mantaro river basin (Central Peruvian Andes)
}

\author{
Y. Silva ${ }^{1}$, K. Takahashi ${ }^{2}$, and R. Chávez ${ }^{1}$ \\ ${ }^{1}$ Instituto Geofisico del Perú, Lima, Perú \\ ${ }^{2}$ NOAA/GFDL, Princeton, New Jersey, USA
}

Received: 16 June 2007 - Revised: 25 September 2007 - Accepted: 25 September 2007 - Published: 10 April 2008

\begin{abstract}
Monthly precipitation data from the period of 1970 to 2004 from 38 meteorological stations in the Mantaro river basin were used to classify the rainy seasons (September-April) of each year into anomalously dry or wet, and to determine the basin-wide extent of the anomalies based on the Standardized Precipitation Index (SPI). The wet periods mostly occurred in the early 1970's and during the first half of the 1980's, except for the event that occurred in the 1993/94 period which was the strongest and most generalized in the analyzed period. The dry periods occurred mostly during the second half of the 1980's and the 1990 's. Consistent with this, a negative trend in precipitation of $2 \%$ per decade was found for the rainy season, due mainly to a stronger trend ( $-4 \% /$ decade) during the peak phase (January-March).

Despite previously reported significant negative correlations between El Niño-Southern Oscillation (ENSO) and rainfall during the peak of the rainfall season, the similar amplitude variability of precipitation during the onset phase of the rainfall season (September-December), which is uncorrelated with ENSO, participate to the reduction of the absolute correlation for the full rainfall season. Correlations between rainfall in the Mantaro basin and sea surface temperature (SST) in the tropical Atlantic are significant only near the end of the rainy season, with more rain associated with a weaker north-south difference in SST in the tropical Atlantic.
\end{abstract}

\section{Introduction}

Precipitation is one of the most important climatological variables in the Mantaro river basin (central Peruvian Andes), due to its great importance in the economic activities of

Correspondence to: Y. Silva

(yamina@chavin.igp.gob.pe) the basin, such as agriculture, energy generation, potable water supply, etc. There are approximately 339.065 hectares of agricultural land on the basin, $71 \%$ of which are unirrigated and depends on precipitation, so droughts are the greatest climatic hazard to agriculture in this region (IGP, 2005a; Martinez et al., 2006).

The main objective of this paper is to analyze the interannual rainfall variability during the rainy season in the Mantaro river basin, classifying years into wet or dry periods and to determine the relationship between the precipitation and the SST anomalies in the Pacific and Atlantic Oceans. For this purpose, historical monthly precipitation time series, from meteorological stations located on the basin, were analyzed in order to identify the rainy and dry years based on the Standardized Precipitation Index. Indices of Niño events and for the south and north tropical Atlantic variability were also used.

\section{Data and methodology}

Monthly precipitation data of 38 meteorological stations for the period 1970-2004 were used. The analysis was made for the rainy season (September-April; see Fig. 1 for the annual rainfall distribution in the basin), which was further divided into onset (September-December) and peak (JanuaryMarch) phases. Additional analysis was done using monthly data.

To determine the anomalously dry and wet rainy seasons, the Standardized Precipitation Index (McKee et al., 1995; Hayas et al., 1999) was used. The SPI for a given averaged period of time is a normalized precipitation anomaly (the difference from the multi-annual mean, divided by the standard deviation), assuming that the mean precipitation for the period of analysis has a normal distribution. A drought event is defined for each time scale as a period in which the SPI is continuously negative and the SPI reaches a value of -1.0 or

Published by Copernicus Publications on behalf of the European Geosciences Union. 


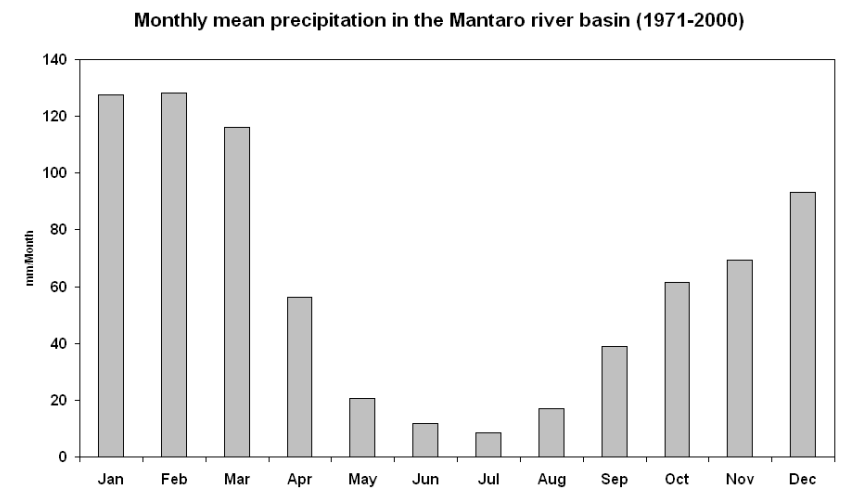

Fig. 1. Climatological monthly precipitation in the Mantaro basin ( $\mathrm{mm} / \mathrm{month}$, average of 38 stations) for the period 1971-2000.

less. The SPI is a very versatile index that allows identifying dry and wet periods on different time scales. The intensity of the rainy events can be also classified using the SPI values proposed by McKee et al. (1993). The SPI is used by the National Drought Mitigation Center - USA for drought monitoring and can also be used to identify and monitoring dry or wet periods.

Dry and wet periods in the Mantaro basin, were defined as such when at least $20 \%$ of the stations presented, respectively, negative and positive values of SPI. The SPI were calculated based on the climatology calculated over the period 1971-2000.

To analyze the relation between precipitation in the Mantaro basin and the SST anomalies in the tropical Pacific and Atlantic, the following SST indices were used: monthly SST indices for standard Niño regions indices provided by NCEP/CDC, the North Tropical Atlantic index (NTA; SST averaged in the composite region $6^{\circ} \mathrm{N}-18^{\circ} \mathrm{N}, 60^{\circ} \mathrm{W}-$ $20^{\circ} \mathrm{W}$ and $\left.6^{\circ} \mathrm{N}-10^{\circ} \mathrm{N}, 20^{\circ} \mathrm{W}-10^{\circ} \mathrm{W}\right)$ and South Tropical Atlantic index (STA; $\left.18^{\circ} \mathrm{S}-6^{\circ} \mathrm{S}, 30^{\circ} \mathrm{W}-10^{\circ} \mathrm{E}\right)$ provided by NOAA/ESRL. With respect to the precipitation data, the individual station data, as well as an average of all stations available for each month, were used.

\section{Results}

\subsection{Seasonal variability}

The amplitude of the rainfall annual cycle is relatively large, with maximum values occurring between January and March and minima between June and July (Fig. 1). Significant precipitations start taking place in September, increase progressively in the following months and decay abruptly in April. For that reason, the most important agricultural activities in the basin are developed between September and April, when $92 \%$ of the annual precipitation takes place, while almost $50 \%$ of the annual precipitation occurs in the peak phase and $35 \%$ falls in the onset phase. A more detailed description of

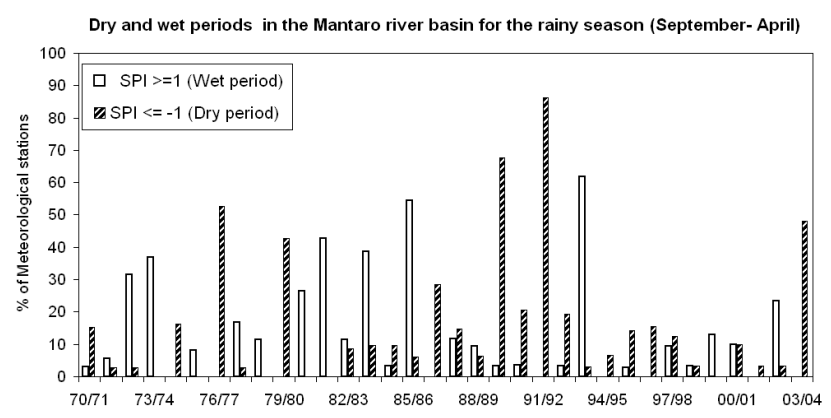

Fig. 2. Percent of stations in which the SPI for the rainy season is equal or greater than 1 (wet period, clear bars) and where SPI is equal or less than -1 (dry period, hatched bars).

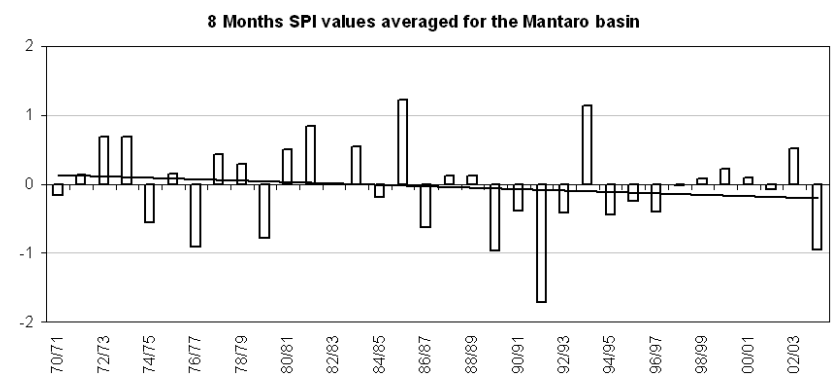

Fig. 3. Rainy season SPI values, averaged for the 38 meteorological stations in the Mantaro basin during 1960-2004. A long term linear trend fit is also displayed ( -0.11 per decade).

the spatial and temporal distribution of rainfall in the basin can be found in IGP (2005c).

\subsection{Interannual variability}

The analysis of the rainy seasons (September to April) in the period between 1970 and 2004 indicates that the following years were anomalously wet: 1972/73, 1973/74, 1980/81, 1981/82, 1983/84, 1985/86, 1993/94 and 2002/03 (see Fig. 2). Out of these, the periods $1993 / 94$ and 1985/86 had the most widespread wet anomalies in the basin: $62 \%$ and $55 \%$ of the stations registered precipitation above their normal, respectively.

The dry periods identified between 1970 and 2004 are: 1976/77, 1979/80, 1986/87, 1989/90, 1990/91,1991/92 and 2003/04. The driest period took place from 1989 to 1993. The seasons with the most widespread dry anomalies were $1991 / 1992$ and $1989 / 90$, when $86 \%$ and $68 \%$ of the stations presented deficit of precipitation, respectively. The 91/92 drought in the Mantaro basin occurred during the moderate 1992 El Niño event. However the other dry periods, as well as the wet $93 / 94$ period, took place during "neutral" year (i.e. without significant ENSO anomalies).

The SPI time series for each station were also analyzed and we found that after the years 1986-1987 the dry periods became more frequent in almost $75 \%$ of the stations, leading 


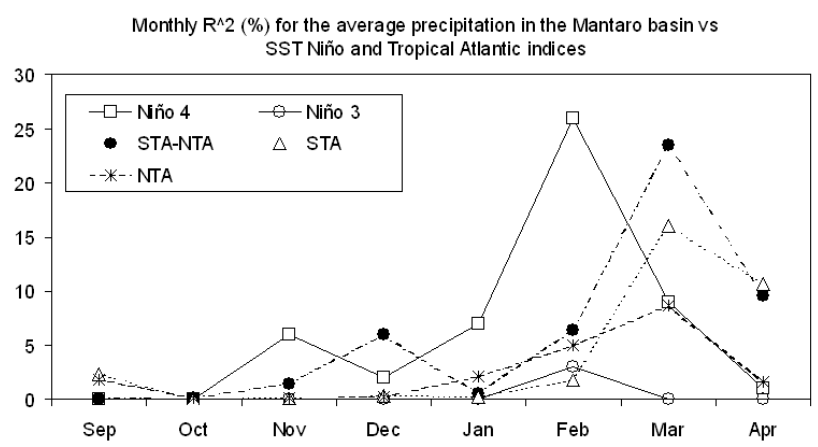

Fig. 4. Percentage of the variance of the average precipitation in the Mantaro basin explained (correlation coefficient squared) by different SST indices: Niño 4, Niño 3, North Tropical Atlantic (NTA), South Tropical Atlantic (STA) indices and the difference between STA and NTA.

to a negative trend in SPI (Fig. 3). In general, the precipitation trend observed during the last 40 years is negative in the northern and central parts of the Mantaro basin, including the valley, whereas in the western and central South part, the trend is slightly positive. The trends, based in the period of 1971-2000, indicate a decrease in precipitation of around $3 \%$ per decade (IGP, 2005b; Silva et al., 2006). We found that for rainfall averaged over all stations in the basin, there is a negative trend in the full rainy season precipitation $(-2 \%$ per decade; $-1.4 \% /$ decade for the full year), which is mostly due to the negative trend during the peak phase of the rainy season $(-4 \%$ per decade), whereas the trend is nearly zero for the onset phase.

\subsection{Relation with ENSO}

Previous studies (Lagos et al., 2005; IGP, 2005b) have found significant negative correlations between the warm phase of ENSO and precipitations during the peak phase of the rainy season in the Mantaro basin. This relation is particularly strong with the Niño 4 index (SST anomaly averaged over $160^{\circ} \mathrm{E}-150^{\circ} \mathrm{W}, 5^{\circ} \mathrm{S}-5^{\circ} \mathrm{N}$ ), which indicates an indirect effect of SST on the Mantaro basin, most likely through atmospheric teleconnections (e.g. Garreaud and Aceituno, 2001).

However, the results presented in this study suggest very little, if any, ENSO impact on precipitation. The correlation coefficient between the rainy season precipitation averaged over all the stations and the Niño 4 index is only -0.34 , which is not statistically significant. This apparent inconsistency with previous studies has to be related to the periods under investigation. As seen in Fig. 4, the correlations are largest in February, in the middle of the peak phase, but are quite small during the onset phase (September-December) ${ }^{1}$. Since the variability in the onset phase is comparable to that

\footnotetext{
${ }^{1}$ The correlation of rainfall in the basin with Niño 4 SST is actually positive in November (Nickl, 2007). This was verified for 34 out of 38 stations.
}

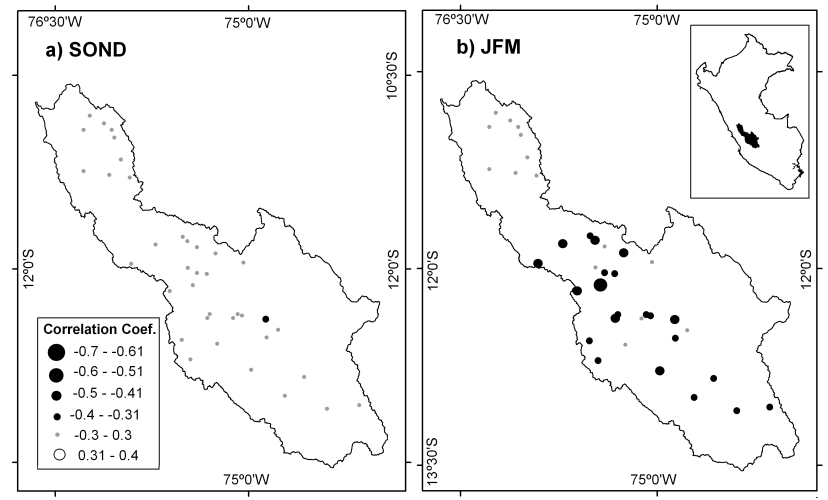

Fig. 5. Correlation coefficients between precipitation and El Niño 4 SST index for (a) the onset and (b) the peak phases of the rainy season. Period of analysis 1960-2004.

in the peak phase (the variances in accumulated rainfall are almost equal), the fact that this variability is uncorrelated with ENSO (Figs. 4 and 5a) lowers the correlation coefficient for the full period. That the variability in the onset and peak phases have similar contributions to that of the entire rainy seasons can be seen by considering the examples of the rainy 1983/84 event, during which the peak phase was rainy, whereas the onset phase was dry, and the case of the dry 1976/77 event, which was mostly due to the dry onset phase.

\subsection{Relation with the Atlantic Ocean}

The rainfall in the Mantaro basin presents significant correlation with the SST in the tropical Atlantic (IGP, 2005b; Nickl, 2007). It peaks in March (Fig. 4) when the northern (southern) tropical Atlantic is cool (warm). Although the values for correlation are larger for the southern region than for the northern region, the largest correlation is reached when the difference between the southern and the northern regions is considered (0.48 in March). This suggests that the meridional SST gradient is more important for influencing the rainfall in the Mantaro basin than SST variability in either the Southern or Northern tropical Atlantic. Previous studies have assessed the importance of this meridional SST dipole pattern (Moura and Shukla, 1981; Nobre and Shukla, 1996; Pezzi and Cavalcanti, 2004), but the modeling experiments reported in Moura and Shukla (1981) and Pezzi and Cavalcanti (2004) do not indicate a robust effect on the Peruvian Andes. This might be due to a shortcoming in the representation of the Andes in the models that might be overcome with the use of higher resolution.

\subsection{Relation with the North Atlantic Oscillation}

Previous studies have shown some relation between rainfall in the Mantaro basin and the North Atlantic Oscillation (NAO) index (IGP 2005b; Nickl, 2007). We found that the 
correlation is highest during October $(-0.35)$, which might provide some limited predictability for this important month for agricultural activities. However, an inspection of the correlation map between sea level pressure (SLP) and the mean rainfall in the basin (not shown) reveals that this correlation results only from a relatively high correlation with the SLP over Greenland and not with the dipolar pattern associated with NAO. The correlation map is quite featureless and does not suggest a physical process that might affect the Mantaro basin, so we believe that the observed correlation might be a sampling artifact rather than an indication of a physical relationship.

\section{Conclusions}

The wet rainy seasons were concentrated mostly in the seventies and in the first half of the eighties, except for the 1993/94 event, which was the largest one. The most recurrent dry rainy seasons occurred in the second half of the eighties and during the nineties; and the two strongest and most generalized dry periods occurred in 1989/90 and 1991/92. Dry periods appear to be becoming more generalized throughout the basin with time, particularly after 1986. A decreasing trend in total rainfall in the rainy season of $2 \%$ per decade was found to be due mainly to the stronger trend during the peak phase $(-4 \% /$ decade), while the trend was almost zero for the onset phase.

Previously reported negative correlation between ENSO (particularly Niño 4 region) and rainfall during the peak of the rainy season overestimate the potential predictability of the full rainy season (September-April). This results from the lack of correlation between ENSO and the significant rainfall variability in the onset phase of the rainy season (September-December). Furthermore, there is a lack of correlation between the rain in this phase and SST anywhere in the Pacific or the Atlantic oceans, suggesting a lack of predictability (relatively high correlations with the NAO index appear to be statistical artifacts). Enhanced predictability, however, might exist near the end of the rainy season, during which a significant correlation exists between rainfall in the basin and the south-north SST difference in the tropical Atlantic (dipole mode).

Acknowledgements. The authors would like to thank the National Peruvian Weather Service (SENAMHI), Electro-Peru and ElectroAndes for providing the station data.

We are also very grateful to P. Aceituno, R. Porfirio, G. Arauzo, L. Ocola, B. Dewitte and to the anonymous reviewers for careful reading of this manuscript and their useful suggestions, and to R. Zubieta for his help in preparation the maps.

K. Takahashi is supported by a NOAA Climate and Global Change postdoctoral fellowship.

Edited by: P. Fabian

Reviewed by: two anonymous referees

\section{References}

Garreaud, R. D. and Aceituno, P.: Interannual rainfall variability over the South American Altiplano, J. Climate, 14, 2779-2789, 2001.

Hayes, M. J., Svoboda, M. D., Wilhite, D. A., and Vanyarkho, O. V.: Monitoring the 1996 Drought Using the Standardized Precipitation Index, B. Am. Meteorol. Soc., 80, 429-438, 1999.

IGP: Diagnóstico de la cuenca del río Mantaro bajo la visión de cambio climático, Fondo Editorial CONAM, Lima, Perú, 2005a.

IGP: Vulnerabilidad y adaptación al cambio climático en la cuenca del río Mantaro, Fondo Editorial CONAM, Lima, Perú, 2005b.

IGP: Atlas Climatológico de precipitaciones y temperaturas en la Cuenca del Mantaro, Fondo Editorial CONAM Lima, Perú, 2005 c.

Lagos, P., Silva, Y., and Nickl, E.: El Niño y la precipitación en los Andes del Perú, Volumen especial Nro. 6 Alberto Giesecke Matto, Sociedad Geológica del Perú, 7-23, 2005.

Martínez, A. G., Núñez, E., Silva, Y, Takahashi, K., Trasmonte, G., Mosquera, K., and Lagos, P.: Vulnerability and adaptation to climate change in the Peruvian Central Andes: Results of a Pilot Study, in: International Conference on Southern Hemisphere Meteorology and Oceanography (ICSHMO), 8., 2006, Foz do Iguaçu. Proceedings, São José dos Campos, INPE, CD-ROM ISBN 85-17-00023-4, 297-305 2006.

Moura, A. D. and Shukla, J.: On the dynamics of droughts in northeast Brazil: observation, theory, and numerical experiments with a general circulation model, J. Atmos. Sci., 38, 2653-2675, 1981.

McKee, T. B., Doesken, N. J., and Kleist, J.: The relationship of drought frequency and duration to time scales, Preprints, Eighth Conf. Appl. Climatol., Anaheim, CA, Am. Meteorol. Soc., 179184, 1993.

McKee, T. B., Doesken, N. J., and Kleist, J.: Drought monitoring with multiple time scales, Preprints, Ninth Conf. Appl. Climatol., Dallas, TX, Am. Meteorol. Soc., 233-236, 1995.

Nickl, E.: Teleconnections and climate in the Peruvian Andes, M.Sc. Thesis, Dept. of Geography, University of Delaware, 2007.

Nobre, P. and Shukla, J.: Variations of Sea Surface Temperature, Wind Stress, and Rainfall over the Tropical Atlantic and South America, J. Climate, 9, 2464-2479, 1996.

Pezzi, L. P and Cavalcanti, I. F. A.: The relative importance of ENSO and tropical Atlantic sea surface temperature anomalies for seasonal precipitation over South America: a numerical study, Clim. Dynam., 17, 205-212, 2001.

Silva, Y., Takahashi, K., Cruz, N., Trasmonte, G., Mosquera, K., Nickl, E., Chavez, R., Segura, B., and Lagos, P.: Variability and climate change in the Mantaro river basin, Central Peruvian Andes. In: International Conference on Southern Hemisphere Meteorology and Oceanography (ICSHMO), 8, 2006, Foz do Iguaçu, Proceedings, São José dos Campos, INPE, CD-ROM ISBN 8517-00023-4, 407-419, 2006. 